\title{
A Brief Outline of the History of the Pancreatic Anatomy
}

\author{
Yusuke Tando $^{\text {a }}$ Miyuki Yanagimachi ${ }^{a}$ Yuki Matsuhashi ${ }^{a}$ Teruo Nakamura ${ }^{b}$ \\ Terumi Kamisawa ${ }^{c}$ \\ ${ }^{a}$ Department of Endocrinology and Metabolism, Hirosaki University School of Medicine, and \\ ${ }^{b}$ Hirosaki University School of Health Sciences, Aomori, and ${ }^{c}$ Department of Internal Medicine, \\ Tokyo Metropolitan Komagome Hospital, Tokyo, Japan
}

\section{Key Words}

nomenclature $\cdot$ Talmud

\begin{abstract}
In the middle of the 18th century, Kouan Kuriyama, a Japanese physician of the Choshu Domain, depicted the anatomy of the human pancreas in a report to his master, Toyo Yamawaki. This report is the first anatomical description of the pancreas in Japan. In the Mediterranean area, the pancreas was apparently first described about 2,000 years before his observation. Although there are quite a few reviews on the history of this complex organ, our brief essay offers a historical outline of the pancreas. Copyright $\odot 2010$ S. Karger AG, Basel
\end{abstract}

\section{Introduction}

Since the Age of Greece, many physicians and anatomists were extremely curious about the 'pancreas'. Their perspectives were unique and interesting. Although there are quite a few reviews [1-6] on the history of this complex organ, our brief essay offers a historical outline of the pancreas.
Human pancreas · Pancreatic anatomy · Pancreatic

\section{The Discovery of the Pancreas - In the World and in Japan}

The Babylonian Talmud contains one of the earliest references to the existence of the pancreas. The Talmud is a compendium of Judaism and Jewish culture, analyzed in depth from 200 BCE to $600 \mathrm{CE}$. In the Talmud, much attention was given to medicine [7]. According to the Russian Jewish physician Judah Leib Benjamin Katzenelson (1846-1917), known by his significant contributions to the study of ancient Hebrew medicine, the pancreas appeared in Tamid as 'finger of the liver' ('ezba' hakabed') and it was considered as an accessory organ of the liver [8]. Tamid is the 9th chapter of Kodshim, volume five of the Babylonian Talmud, which mainly referred to the codes of tabernacle and communion about a ceremony of 'badanahi'.

On the other hand, the ancient Greek anatomists Herophilus (of Chalcedon), Erasistratos, and Eudemus in about $300 \mathrm{BCE}$ also had knowledge about the pancreas [1-5]. Their observation on human cadavers that the organ had no cartilage or bone led Ruphos of Ephesus to name it 'pancreas' (Greek pan: all, + kreas: flesh or meat) in about 100 CE [5] in his work On the Names of Parts of the Human Body.

According to Tsuchiya and Fujisawa [1], in Aristotle's Historia Animalium, there is a line saying 'another to the so-called pancreas'. It is considered that the word pan- 


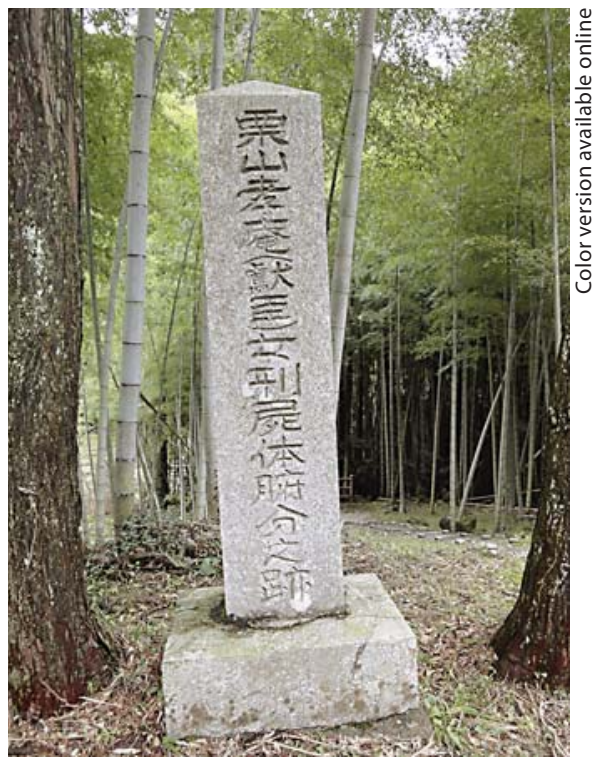

Fig. 1. A monument in memory of the anatomic studies performed by Kouan Kuriyama. He dissected a female cadaver at Oya execution ground of Hagi in 1759. This was the second anatomy in Japan.

creas had been popular at the time of Aristotle (384-322 $\mathrm{BCE}$ ) in the field of zoological or medical studies.

In the 'princeps medicorum', one of the first physicians, Claudius Galenus (Galen: about 129-216 CE), used the word 'kalikreas' which means 'beautiful flesh' for the pancreas. He identified the pancreas as a gland and described the blood vessels lying behind and perhaps supplying it. So it is still under debate who firstly named this organ 'pancreas'.

In Japan, the first reference to the existence of the pancreas is found in an anatomical report by Kouan Kuriyama (1727-1791), a physician of the Choshu Domain, to his medical master Toyo Yamawaki (1706-1762), known by his significant contributions to the medical modernization of Japan, in 1759 (fig. 1). This anatomical report appeared in the book 'Zou bustu yo dan' by Baien Miura (1723-1789), a Japanese natural philosopher and physician [9]. Kouan wrote:

'I observed clumps under the stomach and outside the gut. They were red-yellow in color and about the size of a fist. There were more than a dozen holes on the surface and the reverse like a scar of moxa cautery. The clump adhered to the mesenterium and was hard to remove.'

Thus, Kouan apparently described the pancreas, although he did not name it. The Japanese name of this organ 'Suizo' was firstly called by Genshin Udagawa
(1770-1835), a western (especially Dutch) medical physician (so-called Rangaku-i) in the reference 'han tei kou' in 1805.

\section{The Discovery of the Pancreatic Duct}

Further insight was provided by Johann Georg Wirsung (1589-1643), who first described the main pancreatic duct in 1642 [10]. Although he had no idea as to its function, this finding clearly delineated a new period following the early history of the pancreas, which considered not only its existence but also its function. He engraved his finding on a copper plate and printed several copies. Subsequently, he sent these copies to famous anatomists throughout Europe, asking their opinion concerning the function of the duct [2]. We have to remember the contribution of Moritz Hoffmann, who had seen the duct in an Indian cock and had shown the duct to Wirsung, on the discovery of this duct [10].

Giovanni Domenico Santorini (1681-1737) is credited with the discovery of the accessory pancreatic duct. There were, however, some observations of the minor duct prior to his discovery $[2,11]$. Albrecht von Haller (1708-1777) was the one who reported on the second pancreatic duct [12], but all these observers had considered a double duct as a variant. So the rediscovery of the second pancreatic duct by Santorini led the duct to be termed Santorini duct.

Johann Friedrich Meckel (1781-1833), Professor of Anatomy and Surgery in Halle, Germany, described the minor duct in his Handbuch der pathologischen Anatomie, but considered it as an anomaly presently known as pancreas divisum [2].

\section{The Discovery of the Papilla Duodeni}

Abraham Vater (1684-1751) presented the first description of the tubercle or diverticulum that was later named the 'ampulla of Vater' [13]. Vater noted that the two ducts were fused in a complex fashion and ended as an elevation of the mucosa. The sphincteric muscle surrounding the common bile duct was described in 1654 by the anatomist Francis Glisson (1597-1677) in his article 'Anatomica hepatis' [2]. The sphincter was rediscovered over two centuries after Glisson's report. Ruggero Oddi (1866-1913) described the choledochal sphincter in his article 'D'une disposition a sphincter spécial de l'ouverture du canal choledoche,' which he published in the 1887 volume of Archives Italiennes de Biologie [4]. 


\section{Conclusions}

We have outlined the history of the pancreatic anatomy and nomenclature. The history of this organ spans over 2,000 years, just as the history of medicine. The most important thing we learn from this history is that we discuss the structure together with its function. Pancreatology has now emerged worldwide as a highly specialized discipline in medical sciences. Future research will slake our thirst for knowledge about this complex organ.

\section{References}

1 Tsuchiya R, Fujisawa N: On the etymology of 'pancreas'. Int J Pancreatol 1997;21:269-272.

2 Howard JM, Hess W: History of the Pancreas: Mysteries of a Hidden Organ, revised. New York, Kluwer Academic/Plenum, 2002.

3 Modlin IM, Kidd M: The Paradox of the Pancreas: from Wirsung to Whipple. Hannover, Solvay Pharmaceuticals, 2003

4 Modlin IM, Champaneria MC, Chan AKC, Kidd M, Eick GN: The history of the pancreas: in Beger H, Warshaw A, Büchler M, Kozarek R, Lerch M, Neoptolemos J, Shiratori K, Whitcomb D (eds): The Pancreas, ed 2. London, Blackwell, 2008, pp 9-41.
5 Fitzgerald PJ: Medical anecdotes concerning some diseases of the pancreas; in Fitzsgerald PF, Morrison AB (eds): The Pancreas. Baltimore, Williams \& Wilkins, 1980, pp 1-29.

6 Busnardo AC, DiDio LJA, Tidrick RT, Thomford NR: History of the pancreas. Am J Surg 1983;146:539-550.

7 Bernstein A, Bernstein HC: Medicine in the Talmud. Calif Med 1951;74:267-268.

8 Katzenelson JL: Ha-Talmud ve-Hokhmat haRefu'ah ('Talmud and Medicine'). Berlin, Haim Press, 1928.

9 Miura B, Nakai R: Zou butsu yo dan (Reproduces holographs dated 1781 and 1773); in Ogawa T (Introd): Igaku koten shu 3. Tokyo, Igaku Shuppan, 1958.
10 Howard JM, Hess W, Taraverso W: Johann Georg Wirsung (1589-1643) and the pancreatic duct: the prosector of Padua, Italy. J Am Coll Surg 1998;187:201-211.

11 Suarez CV: The Santorini valves. Mt Sinai J Med 1981;48:149-157.

12 Haller A: Elementa phyusiologiae corporis humani, auctore Alverto ab Haller, 17571766. Bern, Grasset, vol VI, book XXII, p 427.

13 Stern CD: A historical perspective on the discovery of the accessory duct of pancreas, the ampulla 'of Vater' and pancreas divisum. Gut 1986;27:203-212. 